\title{
Fizik Dersi Akademik Özgüven Ölçeği Geliştirme Çalışması ${ }^{1}$ \\ Development of Academic Self-Concept Scale for Physics Course
}

\section{Zeynep Şen Akçay ${ }^{2}$, Nuray Senemoğlü ${ }^{3}$}

\author{
Anahtar Kelimeler \\ akademik özgüven \\ fizik dersi \\ ölçek geliştirme
}

\section{Keywords}

academic self-concept

physics course

scale development

Başvuru Tarihi/Received

13.05.2019

Kabul Tarihi /Accepted

15.10.2019

\section{Öz}

Bu araştırmanın amacı; ortaöğretim öğrencilerinin fizik dersine yönelik akademik özgüvenlerini belirlemeye yönelik geçerli ve güvenilir bir ölçme aracı geliştirmektir. Çalışma grubunda 2015-2016 öğretim yılında Ankara ilindeki MEB'e bağlı devlet Anadolu liselerinde öğrenim gören 515 dokuzuncu sınıf öğrencisi yer almaktadır. Ölçeğin deneme formu ilk aşamada üç farklı Anadolu lisesinde öğrenim gören 274, ikinci aşamada 271 dokuzuncu sınıf öğrencisine uygulanmıştır. Verilerin analizinde ölçeğin yapı geçerliğini belirlemek amacıyla açıklayııı ve doğrulayıcı faktör analizi tekniklerinden yararlanılmıştır. Ölçekten elde edilen verilerin güvenirliğini belirlemek amacıyla Cronbach Alpha katsayısı hesaplanmıştır. Araştırma sonucunda ortaöğretim öğrencilerinin fizik dersine yönelik akademik özgüvenlerini belirlemeye yönelik, olumlu ve olumsuz akademik özgüven olmak üzere iki alt boyuttan oluşan 12 maddelik Fizik Dersi Akademik Özgüven Ölçeği geliştirilmiştir. Ölçekten elde edilen verilerin Cronbach Alpha güvenirlik katsayısı 0.82 ve açıkladığı toplam varyans $\% 48,15$ 'tir. DFA sonucunda ulaşılan ki-kare/serbestlik derecesi oranı 1.71 olup ölçeğin yapısı mükemmel uyum göstermektedir. RMSEA değeri 0.052 olup bu değere göre ölçeğin yapısının modele uyumu iyi düzeydedir. Diğer uyum indeksleri birlikte incelendiğinde geliştirilen ölçeğin 12 maddelik iki boyutlu bir yapıda olduğu doğrulanmıştır. Açıklayııı faktör analizi sonunda iki boyutun ilişkisinin anlamlı olduğu $(r=0.496, p<.01)$, doğrulayıcı faktör analizi sonunda boyutlar arasında pozitif yönde ve yüksek düzeyde $(r=0.66)$ ilişki olduğu belirlenmiştir. Geliştirilen ölçeğin psikometrik özelliklerinin yeterli olduğu bulgularla ortaya konulmuştur.

\section{Abstract}

The aim of this research is to develop a valid and reliable assessment instrument to determine the academic self-concept of secondary school students for physics course. Study group of this research consists of 515 9th grade students from the Anatolian High Schools of the Ministry of National Education in Ankara. The testing form of the scale was firstly applied to 274 9th grade students and was secondly applied to 271 9th grade students who study in 3 different Anatolian High Schools. Explanatory and confirmatory factor analysis technique were used to determine the validity of the scale to analyze the data. Cronbach Alpha parameter was calculated to determine the reliability of the data which obtained from the scale. At the end of the research, a 12-item academic self-concept scale including two sub-dimensions which named positive and negative academic self-concept was developed to determine secondary school students' academic self-concept. The Cronbach Alpha reliability parameter of the data obtained from the scale was 0.82 and the explained total variance was $\% 48,15$. The ratio of chi-square/freedom degrees obtained via DFA was 1.71 and the structure of the scale is perfectly compatible. The RMSEA value is 0.052 and according to this value, the structure of the scale is well adapted to the model. When the other fit indexes are investigated, it is confirmed that the developed scale is a two-dimensional structure with 12 items. At the end of the explanatory factor analysis, it is determined that the relationship between the two dimensions is significant $(r=0.496, p<.01)$, and at the end of the confirmatory factor analysis, it is determined that there is a positive and high correlation between the dimensions $(r=0.66)$. It is demonstrated by findings that the psychometric features of the scale were sufficient.

\footnotetext{
${ }^{1}$ Bu makale Zeynep ŞEN (AKÇAY) tarafından 2018 yılında hazırlanan “Öğrenci ve Öğretme-Öğrenme Süreci Özelliklerinin Fizik Dersi Öğrenme Düzeyini Yordama Gücü" adlı doktora tezinden türetilmiştir.

${ }^{2}$ Hacettepe Üniversitesi, Eğitim Fakültesi, Eğitim Bilimleri Bölümü, Ankara, TÜRKiYE; https://orcid.org/0000-0001-9025-2196

${ }^{3}$ Hacettepe Üniversitesi, Eğitim Fakültesi, Eğitim Bilimleri Bölümü, Ankara, TÜRKIYE; https://orcid.org/0000-0001-9657-0339
} 
Extended Abstract

\section{Introduction}

At the beginning of a new learning unit, students' affective characteristics fairly differ. While some students are concerned, willing and excited, others may feel compelled, unwilling or expect nothing in return. Students must have affective entry characteristics for a better learning. Students who feel that they are successful or can be successful become more interested in new units and their attitudes become more positive. And also, their belief in what they can achieve, in other words, their academic self-concept increases (Bloom, 1976; Özçelik, 2012; Senemoğlu, 1987). Most of the experimental and theoretical studies describe academic self-concept as an important self-concept dimension for school-age individuals (Marsh and Richards, 1987). Academic self-concept is a way of self-perception whether the student can learn any learning unit or cannot, based on their learning background (Senemoğlu, 1989; Senemoğlu, 2018). Academic self-concept is not only fed by previous successes, it also has motivational features that can change the next successes (Bryne, 1984). The academic success in the physics course and the related variables were found to be related to the students at the highest level. Correlation coefficient between the students' previous learning physics and academic achievement was $.25, .20$, having previously taken a mathematics course, and .16 with their attitudes towards the physics course. When the variables related to the class that were taken up together, the coefficient correlation of the academic success of the physics course was determined as .06 . These results showed that student-related variables were more correlated with the success of the physics course than teacher-mediated variables (Lawrenz, Wood, Kirchhoff, Kim and Eisenkraft, 2009). The importance of academic self-concept and success relationship has been an issue that is discussed in literature. Therefore, it can be said that it is both important and necessary to make students feel the academic success and to ensure the continuity of it. At this stage, the aim of the research is to develop a valid and reliable assessment instrument to determine the physics course oriented academic self-concept of secondary school students.

\section{Method}

Study group of this research includes 515 9th grade students from the Anatolian High Schools of the Ministry of National Education in Ankara. The testing form of the scale which consists of 22 items was firstly applied to 2749 th grade students and was secondly applied to 271 9th grade students who study in 3 different Anatolian High Schools. The implementations were made by the researcher and to ensure that the students participate voluntarily, the aim of the study was explained to the students in advance. Obtained data was checked by the researcher and 28 forms were eliminated because of the randomly answered items or the items answered with more than one option or too many unanswered items. For the negative items, reverse coding was made and for the missing values, median designation was made. The data collected in the first stage were used for explanative factor analyze and the data collected at the second stage were used for confirmative factor analyze. Explanatory and confirmatory factor analysis technique were used to determine the validity of the scale to analyze the data. Cronbach Alpha parameter was calculated to determine the reliability of the data which obtained from the scale.

\section{Result and Discussion}

At the end of the study, a 12-item academic self-concept scale consisting of two sub-dimensions, positive and negative academic self-concept, was developed to determine the academic self-concept of secondary school students. The items are coded between 4-0 and the negative points are coded in reverse and then the total score is calculated. According to this code system of this scale, the lowest score is 0 and the highest score is 48 . The high total score indicates that the student has high academic selfconcept in physics courses. The Cronbach Alpha reliability parameter of the data obtained from the scale was 0.82 and the explained total variance was $\% 48,15$. The ratio of chi-square/freedom degrees obtained via DFA was 1.71 and the structure of the scale is perfectly compatible. The RMSEA value is 0.052 and according to this value, the structure of the scale is well adapted to the model. When the other fit indexes are investigated, it is confirmed that the developed scale is a two-dimensional structure with 12 items. At the end of the explanatory factor analysis, it is determined that the relationship between the two dimensions is significant $(r=0.496, p<.01)$, and at the end of the confirmatory factor analysis, it is determined that there is a positive and high correlation between the dimensions $(r=0.66)$. It is demonstrated by findings that the psychometric features of the scale were sufficient. 
GiRiş

Yeni bir öğrenme ünitesinin başlangıcında öğrencilerin duyuşsal yönelimleri büyük farklılıklar gösterir. Bazı öğrenciler ilgili, istekli, heyecanlı iken bazıları zorunluluk hisseden, beklentisiz, ilgisiz olabilir. Eğer tüm öğrencilerin öğrenmeyi istediği bir öğretim ünitesi hazırlanabilirse, öğrencilerin bu öğrenme ünitesine şevkle ve kendilerine daha çok güvenerek başlamaları beklenir. Fakat bu oldukça zordur. Öğrenciler yeni bir üniteye girerken o üniteyle ilgililerse, heyecan duyuyor ve merak ediyorlarsa diğerlerine göre daha kolay ve hızlı öğrenirler. Bir öğrencinin bir üniteyi iyi öğrenebilmesi için, öğrenilecek olan üniteye açık olması, öğrenmeye istek duyması, güçlüklerle karşılaşması halinde bu güçlükleri aşmaya yetecek güç ve çabayı gösterebileceğine güvenmesi gerekir. Öğrencilerin daha iyi öğrenebilmeleri için duyuşsal giriş özelliklerine sahip olmaları gerekir. Bunu sağlamak için öğrencilere başarı hissi tattırılmalıdır. Başarılı olduğunu ya da olabileceğini hisseden öğrencilerin yeni ünitelere karşı ilgileri artar ve tutumları daha olumlu hale gelir. Aynı zamanda başarabileceklerine olan inanışları, yani akademik özgüvenleri artar (Bloom, 1976; Özçelik, 2012; Senemoğlu, 1987).

Deneysel ve kuramsal araştırmaların çoğu, akademik özgüveni (academic self-concept), okul çağındaki bireyler için önemli bir benlik kavramı (self-concept) boyutu olarak tanımlar (Marsh ve Richards, 1987). Olumlu bir benlik kavramı eğitim uygulamalarının birçoğunda istendik bir sonuç olarak değerlendirilir ve sıklıkla akademik başarı gibi diğer istendik çıktılara ulaşılmasını kolaylaştıran bir aracı değişken olarak ifade edilir (Marsh, 1990). Fakat alanyazın giderek artan bir çoğunlukla akademik özgüven kavramının, genel benlik kavramından açıkça ayırt edilebilir olduğunu ve akademik özgüven kavramının akademik başarı ve diğer istendik akademik davranışlarla genel benlik kavramından çok daha fazla ilişkili olduğunu göstermektedir (Byrne, 1984; Marsh, 1986; Marsh, 1990).

Marsh, Byrne ve Shavelson (1988), üç farklı benlik kavramı ölçeği ve bir akademik özgüven ölçeği kullanarak İngilizce, matematik ve genel okul başarı puanı ile benlik kavramı ve akademik özgüven arasındaki ilişkileri araştırmışlardır. Çalışmada, üç benlik kavramı ölçeğinden alınan puanlarla İngilizce, matematik ve genel okul başarı puanı arasında anlamlı ilişki bulunmazken, akademik özgüven puanları ile büyük ölçüde anlamlı ilişkiler tespit etmişlerdir. Akademik özgüvenin hem genel benlik kavramından farklılığı hem de akademik başarıyla ilişkisinin çok daha anlamlı olduğu böylelikle ortaya koyulmuştur.

Brookover, Thomas ve Paterson (1964), benlik kavramının farklı konu alanlarında farklılık gösterdiğini belirtmiş ve konu alanlarına özgü kendini algılayış biçimini, alana özel benlik kavramı (spesific self-concept) olarak isimlendirmişlerdir. Araştırmalarında matematik, İngilizce, sosyal bilimler ve fen bilimleri alanlarına özel benlik kavramı puanlarıyla genel benlik kavramı puanlarının akademik başarıyı yordama güçlerini karşılaştırmışlardır. Brookover, Thomas ve Paterson'ın çalışmalarındaki belli bir alana özel benlik kavramı, sonraki çalışmalarda akademik özgüven olarak isimlendirilmiştir.

Akademik özgüven, öğrencinin öğrenme özgeçmişine dayalı olarak herhangi bir öğrenme birimini öğrenip öğrenemeyeceğine dair dair kendini algılayış tarzıdır (Senemoğlu, 1989; Senemoğlu, 2018). Akademik özgüven, önceki başarılardan beslenmekle birlikte, sonraki başarılarda da değişiklik yaratma gücüne sahip motivasyonel özellikler taşır (Byrne, 1984).

Calsyn ve Kenny (1977), akademik özgüven ile akademik başarı arasındaki nedensellik ilişkisini ortaya çıkarmak için çaprazlanmış panel korelasyon yöntemini kullanmışlardır. Araştırmaları sonucunda; akademik başarının, akademik özgüven üzerindeki nedenselliğinin oldukça baskın olduğunu ortaya çıkarmışlardır. Dolayısıyla akademik özgüvenin öncelikle daha önceki akademik başarılarının bir sonucu olduğunu ileri sürmektedirler. Bu sonuca göre, akademik özgüveni geliştirmenin en iyi yolu, daha güçlü akademik beceriler geliştirmek, öğrencilerin akademik başarılarını sağlamaktır (Marsh, 1990). Benzer şekilde Marsh'ın (1990) çalışması Calsyn ve Kenny'nin (1977) çalışmasını destekler nitelikte olmakla birlikte, nedenselliğin akademik özgüven ile başarı arasında karşılıklı olduğunu da ortaya koymuştur (Marsh, Byrne ve Yeung, 1999).

Akademik özgüven ile keyif alma, gurur, anksiyete, öfke ve can sıkıntısı gibi duygular arasında kuvvetli bir ilişki vardır. Alanyazında matematik ve fizik gibi sayısal alanlarda akademik özgüven ile duygular arasındaki ilişkinin, Almanca ve İngilizce gibi sözel alanlardakine göre daha güçlü olduğunu ortaya koyan çalışmalara rastlanmaktadır. Bu ilişkiler olumlu duygularla pozitif, olumsuz duygularla ise negatif yönlü ilişkilerdir. Fizik dersine ilişkin akademik özgüven ile en kuvvetli pozitif yöndeki ilişkili olduğu duygular sırasıyla, gurur ve keyif almadır (Götz, Cronjäger, Frenzel, Lüdtke ve Hall, 2010).

Bloom'un (1976) tam öğrenme kuramında duyuşsal giriş özellikleri; öğrencinin yeni öğrenme biriminin başlangıcındaki ilgisi, tutumu ve başarılı olup olamayacağına inancıyla ilgili özelliklerin bütünü olarak tanımlanmıştır ve başarıdaki değişkenliği \% 25 oranında açıklama gücüne sahiptir. Öğrencinin belli bir derse karşı, okula ve kendine ilişkin tutumunun okul başarısıyla olan ilişkisi incelendiğinde, akademik özgüvenin tek başına başarıyla olan ilişkisinin aynı değeri verdiği görülmektedir. Akademik özgüven, öğrencinin başarılı olacağına inanma ve güvenme derecesidir. Okul ve okul öğrenmeleri ile ilgili uzun süre devam eden başarı ve onanma ya da başarısızlık ve reddedilme, okula ve okulda öğrenmeye karşı genel tutum üzerinde etkilidir. Başarıyı tatmanın kendine ve yeteneklerine karşı olumlu tutum geliştirmede önemini vurgulayan Senemoğlu (2018), gelecekteki başarıların temelini oluşturacak olan akademik özgüvenin gelişmesi için her çocuğa kendi gücü ölçüsünde sorumluluk verilerek başarılı olmasının sağlanması ve böylelikle başarıyı tatmasının sağlanması gerektiğini ifade etmektedir.

Uz ve Eryılmaz (1999) araştırmasında öğrencilerin fiziğe karşı tutumlarını etkileyen faktörleri incelemiştir. Bu faktörler içinde önceki başarılar da yer almaktadır. Bu değişkenler arasında fiziğe karşı tutumu etkileyen en önemli faktörler matematikteki başarılar ve önceki başarılar olduğu belirlenmiştir. Öğrencilerin önceki başarılarının ve matematik dersindeki başarılarının fizik dersine yönelik tutumlarında önemli bir faktör olması, öğrencilerin başarılı olmalarının olumlu duyuşsal özellikleri kazanmalarını etkilediği anlamına gelmektedir.

| Kastamonu Eğitim Dergisi, 2020, Vol. 28, No. 3| 
Fizik dersinde farklı öğretim yöntemlerinin denendiği birçok çalışmada (Demircioğlu, 2014; Akbulut, 2013; Büyükkara, 2011), denenen yöntemlerin fizik dersine yönelik duyuşsal özelliklere etkisi ele alınmış ve anlamlı farklılıklara ulaşılamamıştır. Bunlar ve benzeri deneysel çalışmaların uygulama sürelerinin kısıtlı olması, tutum ve özyeterlik gibi uzun sürede değişmeye açık olan duyuşsal özellikler üzerinde denenen yöntemlerin anlamlı fark oluşturmamasına neden olabileceği göz önünde bulundurulmalıdır. Yeşildal (2012) fizik dersi ile ilgili proje çalışmalarına katlan öğrencilerin fizik dersine ilişkin tutumlarını incelemiş ve sekiz ay süren uygulaması sonunda proje çalışmalarının öğrencilerin tutumlarını olumlu yönde değiştirdiğini belirlemiştir.

Fizik dersindeki akademik başarı ile en yüksek düzeyde ilişkili değişkenlerin öğrenciye bağlı değişkenler olduğu görülmüştür. Öğrencilerin önceki öğrenmeleri fizik dersi akademik başarıları arasındaki korelasyon katsayısı 0.25 , daha önce matematik dersi almış olmaları ile 0.20, fizik dersine ilişkin tutumları ile 0.16 'dır. Sınıfa bağı değişkenlerin ise birlikte ele alındığında fizik dersi akademik başarısıyla korelasyon katsayısı 0.06 olarak belirlenmiştir. Bu sonuçlar öğrenciye bağlı değişkenlerin, öğretmen aracılı değişkenlere göre fizik dersi başarısıyla daha fazla ilişkili olduğunu göstermiştir (Lawrenz, Wood, Kirchhoff, Kim ve Eisenkraft, 2009).

\section{Araştırmanın Amacı ve Önemi}

Akademik özgüven ve başarı ilişkisi alınyazında tartışılan önemi bir konu olmuştur. Araştırmalar sonucunda akademik özgüvenin öncelikle önceki başarılardan etkilenerek geliştiği ve sonraki başarılar için de hem motivasyonel bir kaynak olduğu hem de sonraki başarıların güçlü ve anlamlı bir yordayıcısı olduğu belirlenmiştir. Bu nedenle öğrencilere hem akademik özgüven kazandırmak için başarıyı tattırmanın hem de sonraki akademik başarılarını yükseltmek ve sürekliliğini sağlamak için akademik özgüven kazandırmanın iki yönlü olarak önemli ve gerekli olduğu söylenebilir.

Alanyazın taraması sonucunda fizik dersinde akademik özgüven ile ilgili yurtiçinde yapılan araştırmaya rastlanmamıştır. Fizik dersine ilişkin öğrenci tutumları en sık araştırılan duyuşsal özellik olarak karşımıza çıkmaktadır. Oysa akademik özgüven, öğrencinin belli bir derse ve kendine ilişkin tutumunun okul başarısıyla ilişkisini tek başına göstermektedir. Bu nedenle fizik dersinde akademik özgüven ile ilişkili araştırmaların eksik olduğu söylenebilir.

Bu doğrultuda araştırmanın amacı; ortaöğretim öğrencilerinin fizik dersine yönelik akademik özgüvenlerini belirlemeye yönelik geçerli ve güvenilir bir ölçme aracı geliştirmektir. Böylelikle öğrencilerinin ders başarısını diğer duyuşsal özelliklere göre yüksek oranda etkilediği bilinen akademik özgüvenleri belirlenebilecek ve akademik başarılarını yükseltmek ve/veya sürekliliğini sağlamaya yönelik tedbirler almaya yönelik uygulamalara veri sağlayacağı umulmaktadır.

\section{YÖNTEM}

Bu çalışma açıklayıcı ve doğrulayıcı faktör analizlerine dayalı bir ölçme aracı geliştirme çalışmasıdır. Bu yönüyle çalışma, konu ile ilgili var olan durumu betimleme amacıyla yapılan (Karasar, 2005) bir tarama araştırmasıdır. Akademik Özgüven Ölçeği geliştirme aşamaları Çalışma Grubu, Ölçeğin Geliştirilmesi, İşlem ve Verilerin Analizi başlıkları altında detaylı olarak sunulmuştur.

\section{Çalışma Grubu}

Çalışma grubu araştırmanın amacına uygun olarak amaçlı örnekleme yöntemiyle belirlenmiştir. Amaçlı örneklemede araştırmacı kendi yargısını kullanarak araştırmanın amacına en uygun olan grubu belirler (Balcı, 2013). Çalışma grubu 2015-2016 öğretim yılında Ankara ilindeki MEB’e bağı devlet Anadolu liselerinin 9.sınıf öğrencileri arasından seçilmiştir.

Ankara ilinin seçilmesinde; ildeki ortaöğretim kurumlarının lise giriş sınavı puanlarına göre farklı başarı düzeylerinde olması ve ortalamalarının Türkiye ortalamasını yansıtıyor olması, il merkezi ve ilçelerinde farklı okul türlerindeki ortaöğretim kurumlarının bulunması ve sosyo-ekonomik düzeylerinin çeşitlilik gösteriyor olması, öğrenci ve öğretmen sayılarının araştırma için yeterli olması etkili olmuştur (TÜiK, 2014; MEB, 2014). Ayrıca ulaşım kolaylığı, zaman ve maliyet açısından ekonomikliği de Ankara ilinin seçilme nedenleri arasındadır.

Dokuzuncu sınıf öğrencilerinin seçilmesinin nedenleri; fizik dersinin ayrı bir disiplin olarak ilk kez 9. sınıfta yer alması, tüm okul türleri için aynı temel fizik konularının dahil olduğu Fizik Öğretim Programının uygulanıyor olması ve bu sınıf düzeyinde henüz lisans yerleştirme sınavına yönelik alan seçiminin yapılmamış olmasıdır. Alan seçimi sonrasında yapılacak bir araştırmada Fizik dersi alan öğrencilerin (11 ve 12. sınıf FM alanı öğrencileri), Fen ve Matematik alanını seçmiş olmaları nedeniyle, hem öğrenme düzeyi bakımından hem de akademik özgüven açısından homojen olma riski taşıyacağı düşünülmüştür.

Çalışma grubunun seçilmesinde okul türleri belirleyici bir ölçüt olarak alınmıştır. Mesleki ve Teknik liseler ile Din Öğretimi liseleri meslek alanlarına yönelik öğretim yapılması ve Özel Eğitim Meslek Liseleri ise özel eğitime gereksinim duyan bireylere yönelik öğretim yapılması nedeniyle çalışma grubuna dahil edilmemiş, Anadolu liseleri çalışma grubuna dahil edilmiştir. Ankara ilinde en fazla sayıda genel ortaöğretim kurumu bulunan Çankaya ilçesi seçilerek temel eğitimden ortaöğretime geçiş sistemi (TEOG) taban puanlarına göre sıralanmıştır. Bu liselerden ilk \%27'lik dilime girenler üst, son \%27'lik dilime girenler alt, diğerleri orta başarı düzeyi olarak kabul edilmiştir.

Araştırmanın çalışma grubunda alt, orta ve üst başarı düzeyindeki üç farklı Anadolu lisesinde öğrenim gören 515 dokuzuncu sınıf öğrencisi yer almaktadır. Çalışma grubunda yer alan öğrencilerden ilk aşamada 251 öğrenciye ulaşılmış ve ikinci aşamada ise farklı sınıflardaki 264 öğrenciye ulaşılmıştır. Ölçek geliştirme çalışmalarında ulaşılması gereken örneklem büyüklüğü, gözlenen değişken sayısının en az beş-on katı olarak ifade edildiğinden (Tavşancıl, 2002), bu araştırma için hem açıklayıcı hem de doğrulayıcı 
faktör analizlerinde örneklemin, deneme formunda yer alan madde sayısının on katı (22x10=220) üzerinde olmasına dikkat edilmiştir.

\section{Ölçeğin Geliştirilmesi}

Akademik Özgüven (AÖ) ölçeğinin geliştirilme sürecinde ilgili alanyazın taranmış ve geliştirilmiş diğer ölçekler incelenmiştir. Bu doğrultuda araştırmacı tarafından fizik dersine yönelik akademik özgüveni ölçmek üzere 23 deneme maddesi yazılmıştır. Kapsam geçerliğini sağlamak üzere maddelerin fizik dersine yönelik akademik özgüveni belirlemeye uygunluğu ve yeterliği uzmanların görüşüne sunulmuştur. Eğitim Programları ve Öğretim alanında doktora derecesine sahip sekiz uzmana formun elektronik kopyası gönderilmiştir. Uzmanlardan her madde için uygun, düzeltilmeli, uygun değil seçeneklerinden birini işaretlemeleri ve nedenini açıklamaları istenmiştir. Ayrıca uzmanlardan eklenmesi gerektiğini düşündükleri yeni maddeler varsa belirtmeleri istenmiştir. Uzman görüşleri doğrultusunda maddelerde değişiklik ve düzeltmeler yapılmış, eklenmesi önerilen maddeler eklenmiş ve çıkarılması önerilen maddeler deneme formundan çıkarılmıştır. Diğer yandan deneme formu Eğitimde Ölçme ve Değerlendirme alanında doktora derecesine sahip iki uzman tarafından incelenmiş ve gerekli görülen düzeltmeler yapılmıştır.

Altısı olumsuz olmak üzere 22 maddenin yer aldığı AÖ ölçeği deneme formu üç dokuzuncu sınıf öğrencisine ayrı ayrı sesli okuma yaptırılmıştır. Araştırmacı tarafından öğrencilerin ölçek maddelerine verdiği tepkiler incelenmiş ve anlaşılmayan ya da belirgin olmayan ifadeler öğrencilerin anlayacağı biçimde düzeltilmiştir.

Beş dereceli Likert tipi olarak hazırlanan ölçeğin deneme formunda yer alan yönerge ile puanlamanın nasıl yapılacağı açıklanmıştır. Ölçekte yer alan maddeler, ifadenin puanlayıcıyı tanımlama derecesine göre sıfır ile dört arasında puanlanmaktadır. Puanlayıcıdan "Beni çok iyi tanımlıyor (4), Beni iyi tanımlıyor (3), Beni orta düzeyde tanımlıyor (2), Beni çok az tanımlıyor (1), Beni hiç tanımlamıyor (0)" seçeneklerinden kendileri için en uygun olanı işaretlemesi beklenmektedir.

\section{İşlem}

Yirmi iki maddeden oluşan deneme formu ilk aşamada üç farklı Anadolu lisesinde öğrenim gören 274 ikinci aşamada 271 dokuzuncu sınıf öğrencisine uygulanmıştır. Uygulamalar araştırmacı tarafından yapılmış, öncesinde öğrencilere çalışmanın amacı açıklanarak gönüllü olan öğrencilerin katılması sağlanmıştır. Elde edilen veriler araştırmacı tarafından kontrol edilerek rastgele yanıtlanan, fazla sayıda madde boş bırakılan, bir maddeye birden fazla puanlamanın yapıldığı ve tamamlanmadan bırakılan 30 form elenmiş ve ilk aşamada 251, ikinci aşamada 264 öğrencinin yanıtları elektronik ortama aktarılmıştır. Olumsuz maddeler için ters kodlama yapılmış ve kayıp değerlere medyan ataması yapılmıştır. İlk aşamada toplanan veriler açıklayıcı, ikinci aşamada toplanan veriler ise doğrulayıcı faktör analizi için kullanılmıştır.

\section{Verilerin Analizi}

Ölçeğin geçerlik ve güvenirlik çalışmaları, Akademik özgüven ölçeği taslak formu aracılığıyla toplanan veriler analiz edilerek yapılmıştır. Verilerin analizinde ölçeğin yapı geçerliğini belirlemek amacıyla açıklayıcı ve doğrulayıcı faktör analizi tekniklerinden yararlanılmıştır. Öncelikle toplanan verilerin faktör analizine uygun büyüklükte olup olmadığını belirlemek üzere Kaiser Meyer Olkin (KMO) ve Barlett küresellik testleri yapılmıştır. Açıklayıcı Faktör Analizinde (AFA) temel bileşenler analizi kullanılmış ve varimax döndürme tekniğinden yararlanılmıştır. Bu ölçek geliştirme çalışmasında amaç ölçülen değişken üzerindeki varyansı açıklamak olduğundan (Convary ve Hutcoff, 2003) temel bileşenler analizi tercih edilmiştir. Toplam açıklanan varyansa katkısı en yüksek olan maddeleri seçmek amacıyla (Büyüköztürk, 2002), faktör yükü alt sınırı 0.40 olarak belirlenmiştir. Doğrulayıcı Faktör Analizinde (DFA) AFA'da ortaya konulan yapının doğruluğu test edilmiştir. Ölçekten elde edilen verilerin güvenirliğini belirlemek amacıyla Cronbach Alpha katsayısı hesaplanmıştır.

\section{BULGULAR}

Bu bölümde "Akademik Özgüven Ölçeği"nin geçerlik ve güvenirlik bulgularına yer verilmiştir.

\section{Geçerliliğe ílişkin Bulgular}

Ölçeğin yapı geçerliğini test etmek üzere açıklayıcı faktör analizi yapılmıştır. Deneme uygulamasından elde edilen 251 öğrenciye ait puanların Cronbach Alpha güvenirlik katsayısı 0.86 olarak hesaplanmıştır. Verilerin faktör analizine uygun büyüklükte olup olmadığını belirlemek üzere Kaiser Meyer Olkin (KMO) testi yapılmış ve KMO değerinin 0.87 olup verilerin faktör analizine uygun büyüklükte olduğu belirlenmiştir. Barlett küreselik testi sonucunda kikare değeri anlamlı bulunmuş $\left(x^{2}=1878.11 p<.01\right)$, verilerin faktör analizine uygun olduğu görülmüştür.

Akademik özgüven ölçeği deneme formunda yer alan 22 maddeye 251 öğrencinin verdiği yanıtların oluşturduğu veri setine temel bileşenler analizi yapılmış, döndürme işlemi uygulanarak faktörler belirlenmiştir. illk analiz sonucunda elde edilen özdeğer yamaç grafiği ve döndürülmüş bileşenler matrisi birlikte incelendiğinde; ölçek maddelerinin dört boyuta dağıldığını göstermekte ve iki boyutta toplanmaya yakın olduğuna işaret etmektedir. Açıklanan toplam varyans \%51,53’tür. 
Maddelerin özdeğerleri döndürülmüş bileşenler matrisinden incelenerek, birden fazla boyutta yer alan ve/veya özdeğeri 0.40'ın altında olan 10 madde $(1,2,4,6,7,9,14,16,17$ ve 18. maddeler) sırayla ölçekten çıkarılmış ve analizler tekrarlanmıştır. Elenen 10 maddeden sonra ölçekte kalmasına karar verilen 12 madde ile tekrar temel bileşenler analizi yapılmıştır. Akademik özgüven ölçeğinin nihai formunda yer almasına karar verilen 12 madde için yapılan analiz sonucunda elde edilen özdeğer yamaç grafiği Şekil 1'de sunulmuştur.

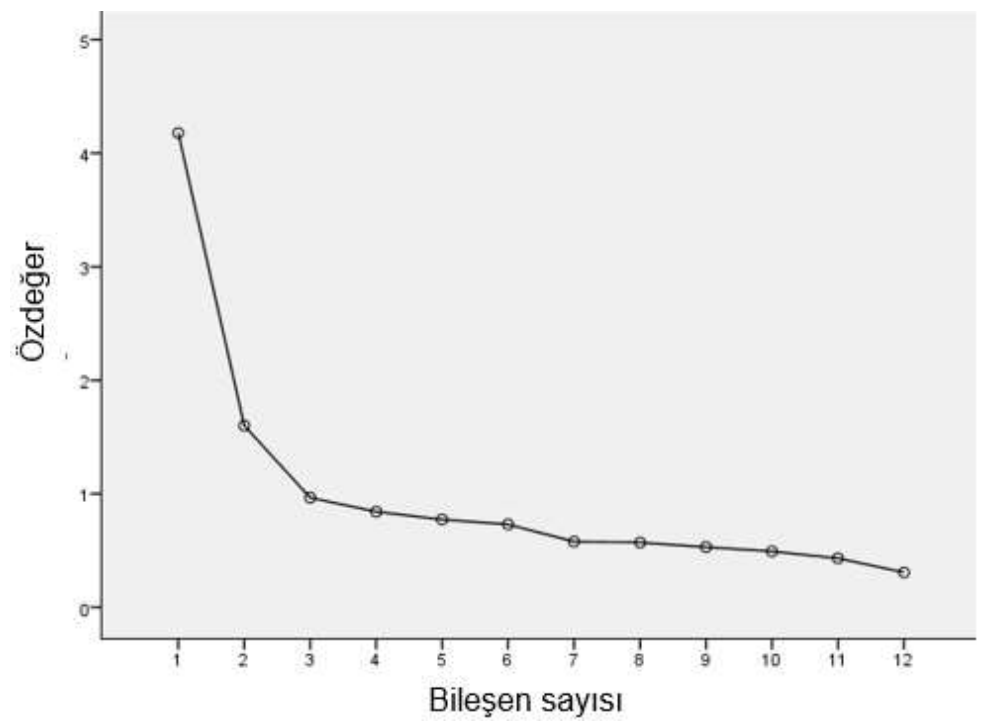

Şekil 1. Akademik özgüven ölçeği nihai formu özdeğer yamaç grafiği

Şekil 1'de görüldüğü gibi özdeğer yamaç grafiği, ölçek maddelerinin iki boyutta toplandığına işaret etmektedir. Maddelerin boyutlara dağılımını ve özdeğerlerini gösteren döndürülmüş bileşenler matrisi Tablo 1'de sunulmuştur. Nihai ölçekte yer alan tüm maddelerin özdeğerleri 0.50'nin üzerindedir.

Tablo 1. Akademik özgüven ölçeği nihai formu döndürülmüş bileşenler matrisi

\begin{tabular}{|c|c|c|c|}
\hline & \multirow{2}{*}{ Maddeler } & \multicolumn{2}{|c|}{ Boyutlar } \\
\hline & & 1 & 2 \\
\hline \multirow{7}{*}{$\frac{\frac{\partial}{\bar{\varepsilon}}}{\frac{\mathfrak{J}}{\partial}}$} & Madde 21: Fizik dersinde verilen görevleri başarabilirim. & .786 & \\
\hline & Madde 22: Fizikle ilgili konuları kolayca öğrenebilirim. & .742 & \\
\hline & Madde 19: Fizik konularını dersi dinleyerek öğrenebilirim. & .708 & \\
\hline & Madde 15: Fizik dersinde sınıf arkadaşlarımdan daha başarılı olacağıma inanıyorum. & .704 & \\
\hline & Madde 20: Fizik dersinde öğretmenin sorduğu soruları cevaplamak için parmak kaldırırım. & 673 & \\
\hline & Madde 13: Fizik dersi çalışarak başarılı olabileceğim bir derstir. & 630 & \\
\hline & Madde 11: Fizik dersinde, özel bir yardım (özel ders, dershane vs.) almadan başarılı olabilirim. & .578 & \\
\hline \multirow{5}{*}{ 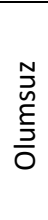 } & Madde 10: Fizik dersinde verilen ödevlerin üstesinden gelemem. & & .727 \\
\hline & Madde 12: Fizik dersinden diğer derslere göre daha düşük notlar alacağımı düşünüyorum. & & .712 \\
\hline & Madde 8: Fizik dersine ne kadar çalışsam da başarılı olamam. & & .653 \\
\hline & Madde 3: Fizik sorularını (problemlerini) anlamakta zorlanırım. & & .610 \\
\hline & Madde 5: Fizikle ilgili konuları öğrenmekte zorlanırım. & & .502 \\
\hline
\end{tabular}

Tablo 1'de görüldüğü üzere nihai ölçekte yer alan tüm maddelerin özdeğerleri .50’nin üzerindedir. Akademik özgüven ölçeğinin nihai formunda yer alan 12 maddenin yedi tanesi ilk boyutta olup olumlu akademik özgüven ifadelerinden oluşmakta ve beş tanesi ikinci boyutta yer alıp olumsuz akademik özgüven ifadelerinden oluşmaktadır. Ölçeğin boyutları arasındaki ilişki Tablo 2'de sunulmuştur.

Tablo 2. Boyutlar Arasındaki Korelasyon Katsayıları

\begin{tabular}{lcc}
\hline Boyutlar & Olumlu & Olumsuz \\
\hline Olumlu & 1.00 & $.496^{*}$ \\
Olumsuz & & 1.00 \\
\hline
\end{tabular}

${ }^{*} p<0.01$

Tablo 2'de ölçeğin iki alt boyutu arasındaki Pearson kolerasyon katsayısının anlamlı düzeyde ( $r=0.496, p<.01)$ olduğu görülmektedir. Alt boyutlar arasındaki ilişkinin anlamlı olması ve boyutlarda yer alan maddelerin incelenmesi ile uzman görüşleri (iki eğitimde ölçme ve değerlendirme uzmanı ile iki eğitim programları ve öğretim uzmanı) doğrultusunda ölçeğin boyutlarından toplam puan alınmasının uygun olduğuna karar verilmiştir. Olumlu ve olumsuz akademik özgüven ifadelerinden oluşan 12 maddelik akademik özgüven ölçeğinin açıkladığı toplam varyans \%48,15'tir. 
Ölçeğin faktör analizinden elde edilen iki boyutlu yapısının doğrulanıp doğrulanmadığını test etmek amacıyla doğrulayıcı faktör analizi yapılmıştır. Açıklayıcı faktör analizi sonunda ulaşılan 12 maddelik nihai form, 264 dokuzuncu sınıf öğrencisine yeniden uygulanmış ve yanıtlar doğrulayıcı faktör analizi için kullanılmıştır. Açıklayıcı faktör analizinde belirlenen boyutlar programda işaretlenerek model oluşturulmuş ve yol şeması çıkarılmıştır. DFA ile elde edilen model Şekil 2'de verilmiştir.

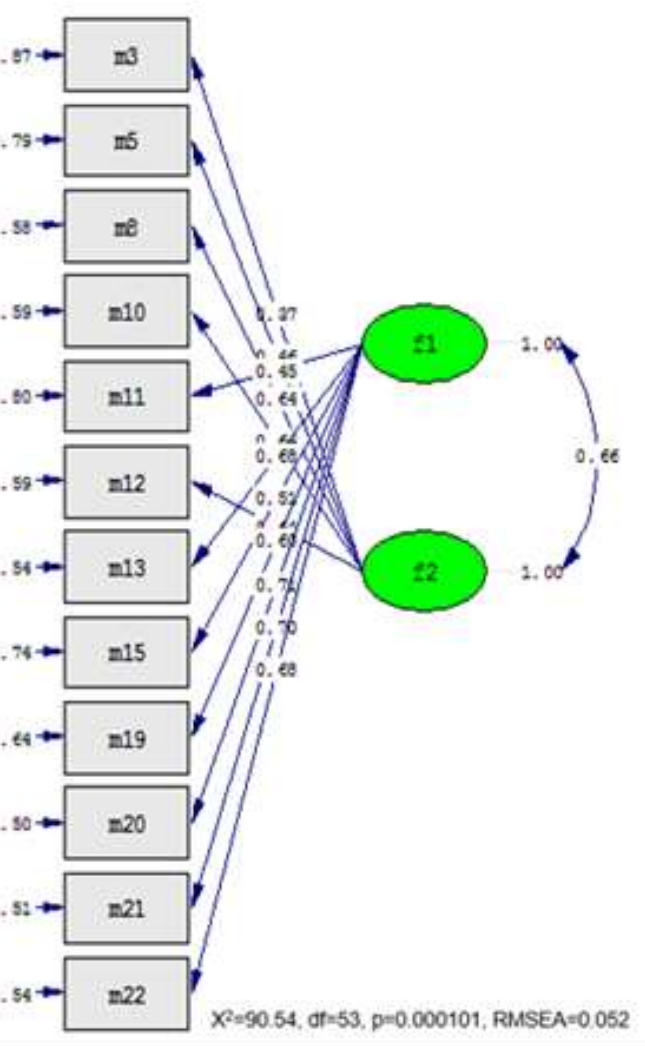

\section{Şekil 2. Akademik özgüven ölçeği yol şeması}

Şekil 2'de verilen yol analizi sonuçları incelendiğinde modelin modifikasyon gerektirmeksizin istatistiksel olarak doğrulandığı görülmektedir. Ölçeğin boyutları arasındaki Pearson kolerasyon katsayısına bakıldığında, boyutlar arasında pozitif yönde ve yüksek düzeyde ( $r=0.66$ ) ilişki olduğu görülmüş ve uzman görüşleri doğrultusunda ölçeğin boyutlarından toplam puan alınmasının uygun olduğuna karar verilmiştir. Akademik özgüven ölçeği ile toplanan verilere uygulanan doğrulayıcı faktör analizi sonucu elde edilen uyum indeksleri Tablo 3'te sunulmuştur.

Tablo 3. Akademik özgüven ölçeği DFA uyum indeksleri

\begin{tabular}{lcc}
\hline Uyum İndeksi & Değeri & Yorum \\
\hline$X^{2} /$ sd & 1.71 & Mükemmel \\
CFI & 0.97 & Mükemmel \\
GFI & 0.95 & Mükemmel \\
NFI & 0.94 & İyi \\
NNFI & 0.97 & Mükemmel \\
AGFI & 0.92 & Mükemmel \\
RMSEA & 0.052 & İyi \\
\hline
\end{tabular}

Tablo 3 incelendiğinde ki-kare/serbestlik derecesi oranının 1.71 olduğu görülmektedir. Bu oranın 3'ün altında olması mükemmel uyum olarak tanımlanmaktadır (Kline, 2005). RMSEA değerine bakıldığında 0.052 olduğu görülmektedir. RMSEA değerinin 0.05 'ten küçük olması mükemmel, 0,08'den küçük olması ise iyi uyum olarak tanımlanmaktadır (Tabachnick ve Fidell, 2007). Diğer uyum indeksleri ile birlikte incelendiğinde geliştirilen ölçeğin 12 maddelik iki boyutlu bir yapıda olduğu doğrulanmıştır.

Açıklayıcı faktör analizi sonunda iki boyutun ilişkisinin anlamlı olması $(r=0.496, p<.01)$, doğrulayıcı faktör analizi sonunda boyutlar arasında pozitif yönde ve yüksek düzeyde $(r=0.66)$ ilişki olduğunun belirlenmesi ve uzman görüşleri doğrultusunda ölçeğin boyutlarından toplam puan alınmasının uygun olduğuna karar verilmiştir.

\section{Güvenirliğe İlişkin Bulgular}

AFA, DFA ve uzman görüşleriyle geçerliği kanıtlanan Akademik Özgüven ölçeğinin ölçüm güvenilirliğini belirlemek üzere Cronbach Alfa iç tutarlılık katsayısı hesaplanmıştır. Ölçek ile elde edilen verilerin Cronbach Alpha güvenirlik katsayısı .82 olarak bulunmuştur. Ölçeğin olumlu ve olumsuz alt boyutları için güvenirlik katsayıları sırasıyla; .83 ve .68 olarak hesaplanmıştır. Ölçekte 
yer alan maddeler ile ölçeğin bütünü arasında korelasyon katsayıları .381 ile .613 arasında değişmektedir. Güvenirliğe ilişkin elde edilen bulgular, bu ölçeğin akademik özgüveni ölçme konusunda güvenilir ölçümler yapmaya uygun bir ölçme aracı olduğunu göstermektedir.

\section{SONUÇ VE ÖNERILER}

Araştırma sonucunda ortaöğretim öğrencilerinin fizik dersine yönelik akademik özgüvenlerini belirlemeye yönelik, olumlu ve olumsuz akademik özgüven olmak üzere iki alt boyuttan oluşan 12 maddelik Fizik Dersi Akademik Özgüven Ölçeği geliştirilmiştir. Ölçeğin uygulama süresi ortalama 10 dakikadır. Maddeler 4-0 arasında kodlanmakta ve olumsuz maddeler ters kodlanarak toplam puan hesaplanmaktadır. Ölçekten alınabilecek en düşük puan sıfır, en yüksek puan 48'dir. Toplam puanın yüksek olması, öğrencinin fizik dersine ilişkin akademik özgüveninin yüksek olduğuna işaret etmektedir. Ölçekten alınan 0-12 aralığındaki puanlar düşük, 1335 aralığındaki puanlar orta ve 36-48 aralığındaki puanlar yüksek akademik özgüvene sahip olmak şeklinde yorumlanmaktadır.

Ölçekten elde edilen verilerin Cronbach Alpha güvenirlik katsayısı 0.82 ve açıkladığı toplam varyans \% 48,15 'tir. Ölçek aracılığıyla elde edilen puanların güvenirlik katsayısının yüksek olması, ölçekte yer alan maddelerin birbiriyle tutarlı olduğu işaret etmektedir. Benzer şekilde madde-test korelasyonlarının pozitif ve .20 üzerinde olması da ölçeğin iç tutarlılı̆ının yüksek (Tezbaşaran, 1996) olduğunu göstermektedir. DFA sonucunda ulaşılan Ki-kare/serbestlik derecesi oranı 1.71 olup ölçeğin yapısı mükemmel uyum göstermektedir (Kline, 2005). RMSEA değeri 0.052 olup bu değere göre ölçeğin yapısının modele uyumu iyi düzeydedir (Tabachnick ve Fidell, 2007). Diğer uyum indeksleri (CFI, GFI, NFI, NNFI ve AGFI) birlikte incelendiğinde geliştirilen ölçeğin 12 maddelik iki boyutlu bir yapıda olduğu doğrulanmıştır. Açıklayıcı faktör analizi sonunda iki boyutun ilişkisinin anlamlı olduğu ( $r=0.496, p<.01)$, doğrulayıcı faktör analizi sonunda boyutlar arasında pozitif yönde ve yüksek düzeyde ( $r=0.66$ ) ilişsi olduğu belirlenmiştir. Geliştirilen ölçeğin psikometrik özelliklerinin yeterli olduğu bulgularla ortaya konulmuştur. Sonuç olarak, geçerlik ve güvenirlik çalışmalarının bulguları doğrultusunda Fizik Dersi Akademik Özgüven Ölçeği'nin bilimsel araştırmalarda kullanılmaya uygun olduğu söylenebilir.

Fizik Dersi Akademik Özgüven Ölçeği aracılığıyla toplanan verilerin analiz edilmesiyle; araştırmacılar, öğretmenler, okul yöneticileri ve rehberlik servisleri tarafından, öğrencilerin ders başarısını diğer duyuşsal özelliklere göre yüksek oranda etkilediği bilinen (Özçelik, 2012; Lawrenz ve diğerleri, 2009; Marsh, Byrne ve Yeung, 1999; Marsh, 1990; Marsh, Byrne ve Shavelson, 1988; Senemoğlu, 1987; Byrne, 1984; Bloom, 1976) akademik özgüvenleri belirlenebilir. Öğrencilerin akademik özgüvenlerini yükseltmek aracılı̆̆ıla akademik başarılarını yükseltmek ve/veya sürekliliğini sağlamak isteyen öğretmenler ya da alandaki araştırmacılar geliştirilen ölçekten yararlanacağı umulmaktadır.

Araştırmadan elde edilen bulgular doğrultusunda araştırmacılara ve uygulayıcılara yönelik geliştirilen öneriler sırasıyla sunulmuştur:

1. Geliştirilen Fizik dersi akademik özgüven ölçeği aracılığıyla öğretim yılı başında öğrencilerin akademik özgüvenleri belirlenerek, öğretmenlerin öğrencilerini tanıması ve öğretimin öğrenci özelliklerine göre en etkili olacak biçimde planlanması sağlanabilir.

2. Geliştirilen Fizik dersi akademik özgüven ölçeği aracılığıyla lise öğrencilerinin akademik özgüvenleri belli aralıklarla ölçülerek, elde edilen veriler doğrultusunda akademik başarılarını yükseltmek ve/veya sürekliliğini sağlamak üzere öğretim uygulamaları düzenlenebilir.

3. Geliştirilen Fizik dersi akademik özgüven ölçeği aracılığıyla, öğrencilerin akademik özgüvenleri ile fizik dersi ya da fizik dersi başarısıyla doğrudan (örn. Matematik, Türkçe vb.) ya da dolaylı ilişkisi olduğu düşünülen derslerin başarıları karşılaştırılarak, aralarındaki ilişkiler ortaya çıkarılabilir.

4. Geliştirilen Fizik dersi akademik özgüven ölçeğinden yola çıkılarak diğer dersler için de geçerli ve güvenilir veriler elde etmeyi sağlayacak akademik özgüven ölçekleri geliştirilebilir.

\section{Etik Kurul Onay Bilgileri}

Hacettepe Üniversitesi Eğitim Bilimleri Enstitüsü'nün 28.08.2015 tarih ve 433-2610 Sayılı yazısı ile araştırmanın etik açıdan uygun olduğu belirtilmiştir.

\section{KAYNAKÇA}

Akbulut, Ö.E. (2013). Dokuzuncu sınıf kuvvet ve hareket ünitesine yönelik bilgisayar destekli bağlam temelli öğretim etkinliklerinin incelenmesi. (Yayımlanmamış doktora tezi), Karadeniz Teknik Üniversitesi Eğitim Bilimleri Enstitüsü, Trabzon.

Balcı, A. (2013). Sosyal bilimlerde araştırma. Ankara: Pegem.

Bloom, B.S. (1976). Human characteristics and school learning. McGraw-Hill.

Brookover, W.B., Thomas, S., \& Paterson, A. (1964). Self-concept of ability and school achievement. Sociology of education, 271-278.

Büyükkara, S. (2011). ilköğretim 8. sınıf fen ve teknoloji dersi ses ünitesinin bilgisayar simülasyonları ve animasyonları ile öğretiminin öğrenci başarısı ve tutumu üzerine etkisi. (Yayımlanmamış yüksek lisans tezi), Selçuk Üniversitesi Eğitim Bilimleri Enstitüsü, Konya.

Büyüköztürk, Ş. (2002). Faktör analizi: Temel kavramlar ve ölçek geliştirmede kullanımı. Kuram ve Uygulamada Eğitim Yönetimi Dergisi, 8(4), 470483. 
Byrne, B.M. (1984). The general/academic self-concept nomological network: A review of construct validation research. Review of educational research, 54(3), 427-456.

Conway, J. M. ve Huffcutt, A. I. (2003). A review and evaluation of exploratory factor analysis practices in organizational research. Organizational research methods, 6(2), 147-168.

Demircioğlu, S. (2014). Örnek olaya dayalı öğrenme yönteminin lise öğrencilerinin fizik dersinde kavramsal anlamaları ve özyeterlik inançları üzerindeki etkileri. (Yayımlanmamış yüksek lisans tezi), Dokuz Eylül Üniversitesi Eğitim Bilimleri Enstitüsü, İzmir.

Götz, T., Cronjäger, H., Frenzel, A.C., Lüdtke, O., \& Hall, N.C. (2010). Academic self-concept and emotion relations: Domain specificity and age effects. Contemporary Educational Psychology, 35(1), 44-58.

Karasar, N. (2005). Bilimsel araştırma yöntemi. Ankara: Nobel.

Kline, T. (2005). Psychological testing: A practical approach to design and evaluation. California: Sage.

Lawrenz, F., Wood, N.B., Kirchhoff, A. Kim, N.K., \& Eisenkraft, A. (2009) Variables Affecting Physics Achievement. Journal of Research in Science Teaching. 46(9). 961-976.

Marsh, H.W. ve Richards, G.E. (1988). Tennessee Self Concept Scale: Reliability, internal structure, and construct validity. Journal of Personality and Social Psychology, 55(4), 612-624.

Marsh, H.W. (1986). Verbal and math self-concepts: An internal/external frame of reference model. American Educational Research Journal, 23(1), 129-149.

Marsh, H.W. (1990). Causal ordering of academic self-concept and academic achievement: A multiwave, longitudinal panel analysis. Journal of Educational Psychology, 82(4), 646-656.

Marsh, H.W., Byrne, B.M. ve Shavelson, R.J. (1988). A multifaceted academic self-concept: Its hierarchical structure and its relation to academic achievement. Journal of educational psychology, 80(3), 366.

Marsh, H.W., Byrne, B.M. ve Yeung, A.S. (1999). Causal ordering of academic self-concept and achievement: Reanalysis of a pioneering study and revised recommendations. Educational psychologist, 34(3), 155-167.

MEB. (2014). Eğitim İstatistikleri. http://ankara.meb.gov.tr/www/egitim-istatistikleri/icerik/24 adresinden erişildi.

Özçelik, D.A. (2012). Insan nitelikleri ve okulda öğrenme (2.baskı). Ankara: Pegem Akademi.

Senemoğlu, N. (1987). Tam öğrenme modeli-yararları ve sınırılıkları. Eğitim ve Bilim Dergisi, 2(66), 28-33.

Senemoğlu, N. (1989). Öğrenci giriş nitelikleri ile öğretme-öğrenme süreci özelliklerinin matematik derslerindeki öğrenme düzeyini yordama gücü. Ankara: Hacettepe Üniversitesi Eğitim Bilimleri Bölümü.

Senemoğlu, N. (2018). Gelişim öğrenme ve öğretim (25.baskı). Ankara: Anı.

Tabachnick, B.G. ve Fidell, L.S. (2007). Using multivariate statistics. USA: Pearson Education, Inc.

Tavşancıl, E. (2002). Tutumların ölçülmesi ve SPSS ile veri analizi. Ankara: Nobel.

Tezbaşaran, A. (1996). Likert tipi ölçek geliştirme kılavuzu. Ankara: Psikologlar Derneği.

TÜiK. (2014). Eğitim İstatistikleri. http://www.tuik.gov.tr/PreTablo.do?alt_id=1018 adresinden erişildi.

Uz, H. ve Eryılmaz, A. (1999). Effects of socioeconomic status, locus of control, prior achievement, cumulative gpa, future occupation and achievement in mathematics on students' attitudes toward physics. Hacettepe Üniversitesi Eğitim Fakültesi Dergisi, 16-17, 105-112.

Yeşildal, G.N. (2012). Fizik proje çalışmalarına katılan lise öğrencilerinin fizik dersine karşı tutumlarındaki gelişmeler. (Yayımlanmamış yüksek lisans tezi), Gazi Üniversitesi Eğitim Bilimleri Enstitüsü, Ankara. 